\title{
Agricultural adaptation and climate change policy for crop production in Africa
}

\begin{abstract}
Africa is considered among the most highly vulnerable regions to climate change because of extremes of drought, flooding, inappropriate land tenure systems, overdependence on rainfed agriculture, and widespread poverty. The impact of climate change is moderated by several factors such as access to land, inputs, credit, and markets. Thus, there is a critical need for decision makers at different levels in Africa to develop matching response strategies and policies to reduce vulnerability and foster resilient livelihood systems on a sustainable basis. The smallholder farming communities are inherently the most vulnerable to the negative impacts of climate change, and are always away from the advantage of any emerging opportunities due to resource constraints. About $65 \%$ of national agricultural earnings in this continent is derived from the crop production of staple cereals, particularly maize. Due to shrinkage in cultivated area, production is also about $5 \mathrm{i} 25 \%$, and the regionôs need is more chronic for food and feed. The climate change challenge is aggravated by diminishing soil productivity and the decline in natural resources has affected the livelihood of rural and periurban communities. The communities have drawn on their indigenous knowledge systems with the support of local institutions and traditional social safety nets to adopt the various multiple stress factors related to climate change and variability. However, there is still limited empirical evidence on the robustness of these systems in support of social collaborations and resolving conflicts arising from the resource scarcity in the wake of climate change. Comprehensive policy frameworks are therefore required to expand the climate change adaptation horizons beyond the boundaries of current farming systems. For instance, the risk of crop-based enterprises has increased by deteriorating climatic conditions. There is much evidence of multiple stresses characterising the existing poverty traps for the predominantly rural communities, and challenges of chronic food insecurity, but no evidence on how current agriculture and climate change policy frameworks are able to address these multiple stress factors against the increasing risk and uncertainty of agriculture as a source of climate change adaptation. Currently, the majority of the farmers lives beyond the reach of markets, yet agricultural development policies are hinged on the principles of market participation. Transformation of these subsistence farms into commercially oriented and market-driven production systems will effectively call for structural and process changes in knowledge systems, technology development and delivery, institutions, and policies. The empirical research shows evidence of current and future impacts of climate change and variability on agricultural production systems, and their implications on the resilience of smallholder farming systems currently supporting the poorer and more vulnerable communities. Over the past decade, there has been a remarkable increase in awareness about climate change issues with diverse stakeholders, including policy makers. The lack of knowledge on the nature, magnitude, and direction of impacts at the indigenous community and national scales will likely continue to haunt decision-making processes regarding the development of robust strategies and policies to support adaptation. However, the regional agricultural sector has to undergo major transformation processes in order to meet emerging demands for adaptation.
\end{abstract}


This may entail changes in the types and forms of information, knowledge, technologies, resource regimes, and institutions driving current production systems. There are still major knowledge gaps across disciplines on how local-level changes in climatic factors influence the socioecological processes that underpin agricultural production systems across spatial and temporal scales. Thus, it has been concluded that the policy making on climate change in Africa is not necessarily constrained by the lack of empirical evidence, but instead by the failure of policy makers to use available empirical evidence. The current failures in linking research to policy could be a major barrier to further research and development innovations for climate change adaptation. Evidence from limited climate change adaptation studies conducted with communities in the region revealed the importance of policy dialogue platforms as an integral part of research and development initiatives.

Keyword: Climate change adaptation; Crop production; Environmental risks; Policy makers; Smallholders 